\title{
Synthesis of Enantiomerically Enriched Amino Acids Containing Acetylenic Bond in the Side-Chain Radical
}

\author{
Ashot. S. Saghyan, Anna F. Mkrtchyan, Ani J. Karapetyan, Zorayr Z. Mardiyan, Liana A. Hayriyan, and \\ Hayarpi M. Simonyan
}

\begin{abstract}
An efficient method for the asymmetric synthesis of enantiomerically enriched derivatives of (S)-propargylglycine by C-alkylation of $\mathrm{Ni}^{\mathrm{II}}$-complex of Schiff's bases of propargylglycine and chiral auxiliary (S)-2-N-[N'-(benzylprolyl) amino] benzophenone with benzyl bromide and its derivatives (de 85-90 \%) has been developed. This resulted in synthesis of new enantiomerically enriched $\alpha$-amino acids containing acetylenic bond in the side chain (ee >95\%).
\end{abstract}

Index Terms-Asymmetric synthesis, enantiomerically enriched $\alpha$-amino acid, acetylenic bond.

\section{INTRODUCTION}

Unnatural amino acids constitute more and more attractive targets for drug design, and their asymmetric synthesis has been increasingly developed over the last decades. It is well known that non-proteinogenic amino acids incorporation in peptide sequences increases resistance to enzymatic proteolysis [1]. Moreover, disposing of a wide variety of unnatural amino acids allows the modulation of physical and chemical properties of the resulting peptides depending on the selected side chains [2]. In this domain, unsaturated amino acids represent very interesting building blocks. Indeed, alkenyl- or alkynyl side chains can be functionalized by many chemical functions and offer a wide range of possible transformations. Particularly unsaturated $\alpha$-amino acids give access to many synthetic applications in all fields of chemistry. Among them, metal catalyzed cross-coupling reactions and cross metatheses are commonly used to generate peptide modifications [3], [4] and cyclizations [5].

Manuscript received April 17, 2016; revised August 17, 2016. This work was supported in part by the RA MES State Committee of Science and Russian Foundation for Basic Research $(R F)$ in the frames of the joint research projects SCS $15 \mathrm{RF}-035$ and also was supported by the RA MES State Committee of Science, in the frames of the research project №15T-1D260.

Ashot. S. Saghyan, Anna F. Mkrtchyan, Ani J. Karapetyan, and Hayarpi M. Simonyan are with the SPC "Armbiotechnology" SNPO NAS RA, and is with chair the Pharmchemistry and Pharmacognosy of Yerevan State University, Republic of Armenia (e-mail: saghyan@netsys.am, anna_mkrtchyan@ysu.am,paruhiani@mail.ru, hayarpi@yandex.ru).

Z. Z. Mardiyan and L. A. Hayriyan are with the SPC "Armbiotechnology" SNPO NAS RA, Republic of Armenia (e-mail: zmardiyan@mail.ru, lianahayriyan@mail.ru).
They can also be substrates of biological interest for fluorination for example as PET radiotracers [6]. They are very interesting and useful tools for "click" chemistry [7], [8] in peptidomimetic drug design or covalent modification of proteins [9]. They can also be incorporated in compounds as beta-turn inducer to promote secondary structures [10]. Finally they can be used for the preparation of stapled peptides. Stapled peptides were first designed by Verdine as a hydrocarbon staple that 'locked' a flexible peptide into the shape of an alpha-helix by reaction of two $\alpha, \alpha$-disubstituted non-natural amino acids bearing an olefin side chain [11]. In recent years a great number of papers have appeared on stapled pepides [12] and it has been demonstrated that also monosubstituted alkenyl amino acids are suitable for their preparation [13].

Also amino acids are widely used in medicine, pharmaceutics; they are commercially low-cost enantiomerically enriched key components of many medicinal preparations. In the last 20 years the use of enantiomerically enriched non-protein amino acids containing different aliphatic, aromatic and heterocyclic groups in the side chain have been rapidly developing [14]. Amino acids containing unsaturated bonds in the side-chain radical occupy a special place among these compounds. Thus, for example, $(S)$-propargylglycine isolated from fermentation broth of Streptomyces sp. bacterial strain [15] and from Amanita pseudoporphyria fungi is a potential inactivator of pyridoxal-P dependent $\gamma$-cystathionase [16], inhibits growth of Saccharomyces cerevisiae as well as synthesis of amylase [17]-[23], affects activity of ATP: L-methionine $S$-adenosyltransferase [24].

To synthesize unsaturated amino acids, Crisp and Robinson for the first time used Pd-catalytic system in the reactions of C-alkylation of unsaturated groups, in particular, of propargylglycine [25]. Using this approach, Li and coworkers succeeded in producing a number of compounds with acetylenic bond that are thrombin inhibitors [26].

Later on the Procter and Gamble Pharmaceutical Company using the Sonogashira reaction has generated a whole series of phenyl substituted propargylglycine derivatives that became the basis for metalloproteases inhibitors [27]. The similar strategy was employed by the researchers of the Novartis Company who managed to produce enantiomerically pure compounds with a propargyl fragment that are inhibitors of Endothelium-converting enzymes. Using phenyl substituted derivatives of propargylglycine they also succeeded in producing dipeptide nitrile, which was successfully tested as an inhibitor of lysosomal cysteine 
protease cathepsin B [28].

There are several methods to obtain non-proteinogenic amino acids containing acetylene bond in the side chain: isolation from some fungi species alkylation of O'Donnell substrate by unsaturated alkyl halogenide, Strecker and Sonogashira reactions followed by enzymic cleavage.

However, in the majority of cases, racemic precursors were used in synthesis of unsaturated $\alpha$-amino acids and end products were produced in the form of optically inactive racemates. Only in some cases it became possible to provide the enantiomeric yield by enzymic hydrolysis.

\section{RESULTS AND DISCUSSION}

Earlier asymmetric syntheses of different enantiomerically enriched non-protein $(S)$ - $\alpha$-amino acids were carried out by C-alkylation of $\mathrm{Ni}^{\mathrm{II}}$ complex of Schiff's bases of glycine and chiral auxiliary (S)-2-N-[N`-(benzylprolyl)amino]benzophenone (BPB) [29]. The possibility of synthesis of enantiomerically enriched $(S)$ - $\alpha$-amino acids containing unsaturated bonds in the side-chain radical by $\mathrm{C}$-alkylation of the acetylenic moiety of chiral $\mathrm{Ni}^{\mathrm{II}}$ complex of $(S)$-propargylglycine was also shown (Figure). In all reactions chiral macrostructure of $\mathrm{Ni}^{\mathrm{II}}$ complexes provides high stereoselectivity of amino acid conversions (ee > $90 \%)$ [30].

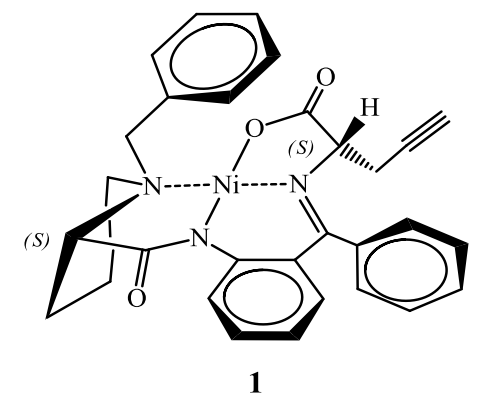

Fig. 1. The structure of $\left.\mathrm{Ni}^{\mathrm{II}}-(S)-\mathrm{BPB}-(S)-\mathrm{PGly}\right)$.

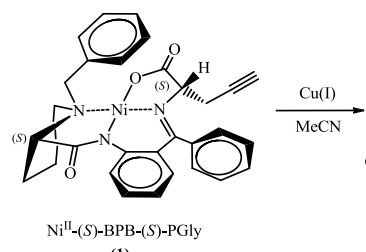

(1)

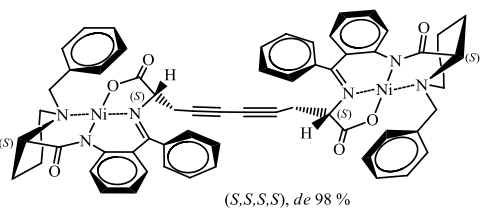

(2)

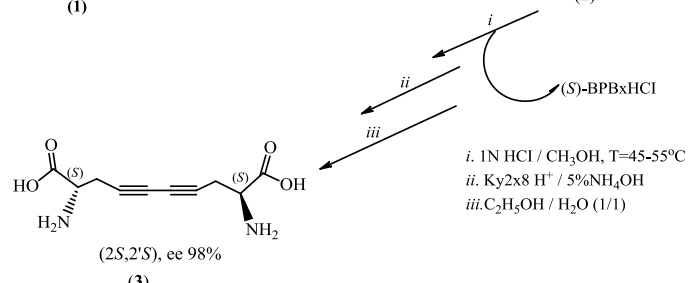

Scheme 1

In this paper we report the synthesis of enantiomerically enriched derivatives of $(S)$-propargylglycine substituted at both $\alpha$-carbon moiety and acetylenic group of propargyl moiety by C-alkylation of chiral $\mathrm{Ni}^{\mathrm{II}}$ complex of Schiff's bases of $(S)$-propargylglycine and $(S)$-BPB $\left[\mathrm{Ni}^{\mathrm{II}}-(S)\right.$-BPB-$\left.\left.(S)-\mathrm{PGly}\right)\right]$.

To obtain dimer of $(S)$-propargylglycine, the oxidative dimerization of complex $\mathrm{Ni}^{\mathrm{II}}-(S)$-BPB-(S)-PGly (1) was carried out at the acetylenic group in $\mathrm{CH}_{3} \mathrm{CN} / \mathrm{K}_{2} \mathrm{CO}_{3}$ in the presence of $\mathrm{CuCl}$ catalyst (see Scheme 1).

The next stage was study of the reaction of C-alkylation of propargylglycine fragment of complex 1 by alkylhalogenides. Allyl bromide, benzyl bromide and its halogen-substituted analogs were used as alkyl halogenides (RX).

The reaction of $\mathrm{C}$-alkylation of amino acid moiety of complex 1 was conducted in $\mathrm{DMF} / \mathrm{NaOH}$ and $\mathrm{MeCN} / \mathrm{K}_{2} \mathrm{CO}_{3} / \mathrm{Cu}(\mathrm{I})$.

As a result it was detected that when conducting the reactions of alkyl halogenides condensation to complex 1 in $\mathrm{MeCN} / \mathrm{K}_{2} \mathrm{CO}_{3}$ in the presence of $\mathrm{CuCl}$, substitution at the acetylenic hydrogen atom occurs only in case of using allyl bromide with the formation of $(S)$-4-allylpropargylglycine complex (4). When benzyl bromides are used as alkylating agent, oxidation dimerization of complex $\mathbf{1}$ with the formation of dimeric complex $\mathbf{2}$ is observed instead of $\mathrm{C}$-alkylation. When the reaction of alkylation is carried out in DMF in the presence of $\mathrm{NaOH}$, substitution of $\alpha-\mathrm{H}$-amino acid residue with the formation of complexes of $\alpha$-alkyl substituted $(S)$-propargylglycines (5a-h) is observed for all halogenides. The major fractions of synthesized complexes (4, 5a-h) were chromatographed and their structures confirmed by spectral methods. Absolute configuration of $\alpha$-carbon atom of amino acid moieties of complexes was assigned by polarimetric measuring [30].

Isolation of the target enantiomerically enriched amino acids (6-14) from the major diastereomeric complexes (4, 5a-h) was conducted according to a general method [31]. Their strictures and absolute configurations were determined by spectral methods.

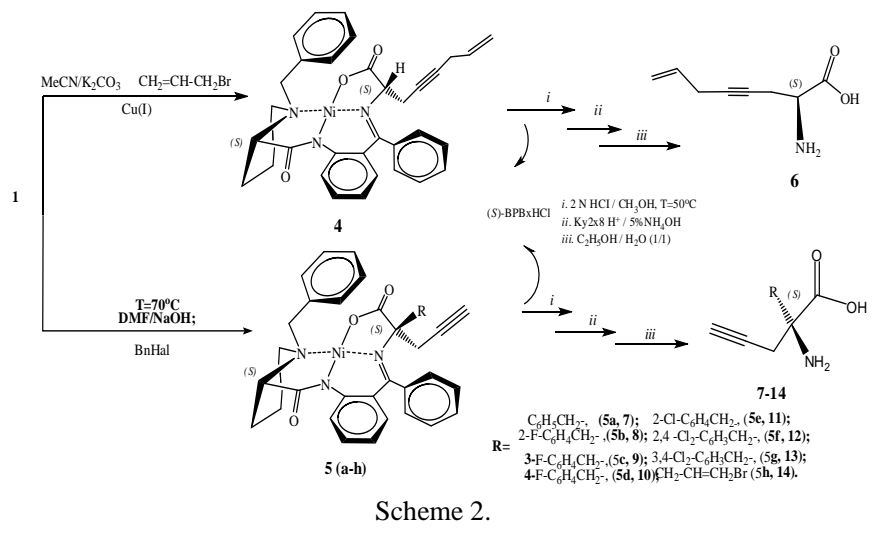

TABLE I: THE RESULTS OF ASYMMETRIC C-ALKYLATION OF $\mathrm{NI}^{\mathrm{II}}-(\mathrm{S})-\mathrm{BPB}-(\mathrm{S})-\mathrm{PGLY}{ }^{\mathrm{A}}$

\begin{tabular}{|c|c|c|c|c|}
\hline \multirow{2}{*}{ № ${ }^{\mathrm{a}}$} & \multirow{2}{*}{$\mathrm{RX}$} & \multicolumn{3}{|c|}{ Alkylated complex } \\
\hline & & $\begin{array}{c}\text { Major } \\
\text { diastereomer }\end{array}$ & $\begin{array}{l}d e \\
\%^{\mathrm{c}}\end{array}$ & $\begin{array}{l}\text { Chem. } \\
\text { yield, } \%{ }^{\text {d }}\end{array}$ \\
\hline 1. & $\mathrm{CH}_{2}=\mathrm{CH}-\mathrm{CH}_{2}-\mathrm{Br}^{b}$ & 4 & 74 & 74 \\
\hline 2. & $\mathrm{C}_{6} \mathrm{H}_{5} \mathrm{CH}_{2} \mathrm{Br}$ & $5 \mathrm{a}$ & 72 & 55 \\
\hline 3. & $2-\mathrm{F}-\mathrm{C}_{6} \mathrm{H}_{4} \mathrm{CH}_{2} \mathrm{Br}$ & $5 b$ & 70 & 52 \\
\hline 4. & $3-\mathrm{F}-\mathrm{C}_{6} \mathrm{H}_{4} \mathrm{CH}_{2} \mathrm{Br}$ & $5 c$ & 68 & 62 \\
\hline 5. & $4-\mathrm{F}-\mathrm{C}_{6} \mathrm{H}_{4} \mathrm{CH}_{2} \mathrm{Br}$ & $5 d$ & 76 & 67 \\
\hline
\end{tabular}




\begin{tabular}{|c|c|c|c|c|}
\hline 6. & 2- $\mathrm{Cl}-\mathrm{C}_{6} \mathrm{H}_{4} \mathrm{CH}_{2} \mathrm{Br}$ & $5 e$ & 73 & 58 \\
\hline 7. & 2.4- $\mathrm{Cl}_{2}-\mathrm{C}_{6} \mathrm{H}_{3} \mathrm{CH}_{2} \mathrm{Cl}$ & $5 f$ & 69 & 68 \\
\hline 8. & 3.4- $\mathrm{Cl}_{2}-\mathrm{C}_{6} \mathrm{H}_{3} \mathrm{CH}_{2} \mathrm{Cl}$ & $5 \mathrm{~g}$ & 71 & 60 \\
\hline 9. & $\mathrm{CH}_{2}=\mathrm{CH}-\mathrm{CH}_{2}-\mathrm{Br}$ & $5 \mathrm{~h}$ & 75 & 55 \\
\hline
\end{tabular}

The ratio of $(S, S)$ - and $(S, R)$-diastereomers of alkylation products was evaluated by ${ }^{1} \mathrm{H}$ NMR analysis of the mixture of diastereomeric complexes (before chromatography) by the ratio of the integral intensities of the signals of methylene protons of N-benzylproline moiety in the range of 2.55-4.40 ppm. Besides, the ratio of diastereomeric complexes was additionally verified by chiral HPLC analysis of the mixture of amino acids obtained after acidic decomposition of the mixture of diastereomeric complexes (before chromatography) and ion-exchange demineralization.

The results of asymmetric c-alkylation of $\mathrm{NI}^{\mathrm{II}}$-(S)-BPB-(S)-PGly are given in Table I.

The results of asymmetric yields target amino acid are given in Table II.

The target $\alpha$-alkyl and aryl substituted propargylglycines (7-14) as well as $(S)$-2-aminoocta-7-en-4-ynoic acid (6) was isolated from the diastereomeric mixtures of alkylated complexes according to the standard procedure and crystallized from aqueous alcoholic solutions.

TABLE II: THE RESULTS OF ASYMMETRIC YIELD OF SYNTHESIZED AMINO ACIDS

\begin{tabular}{|c|c|c|}
\hline \multicolumn{3}{|c|}{ Target amino acid } \\
\hline $\begin{array}{l}\text { Amino } \\
\text { acids }\end{array}$ & ee, $\%^{a}$ & Chem. yield, \% \\
\hline 6 & 98.5 & 71 \\
\hline 7 & 97.5 & 60 \\
\hline 8 & 95.5 & 64 \\
\hline 9 & 96.5 & 71 \\
\hline 10 & 95.0 & 64 \\
\hline 11 & 96.4 & 64 \\
\hline 12 & 97.8 & 64 \\
\hline 13 & 95.3 & 64 \\
\hline 14 & 96.4 & 59 \\
\hline mined & $\begin{array}{l}\text { of ch } \\
\text { of th } \\
\text { dem }\end{array}$ & $\begin{array}{l}\text { of the amino acic } \\
\text { e of diastereomeric } \\
\text { ion. }\end{array}$ \\
\hline
\end{tabular}

The structures and absolute configuration of synthesized amino acids were established by physicochemical methods.

As a result new enantiomerically enriched $(S)$ - $\alpha$-amino acids containing a triple bond in the side-chain radical were obtained.
This amino acids are a key unit in the synthesis of metalloproteases inhibitors.

\section{REFERENCES}

[1] F. Roberto, L. J. Julien, A. René, J. Martinez, and F. Cavelier, Amino Acids, vol. 47, p. 1107, 2015.

[2] L. Gentilucci, R. De Marco, and L. Cerisoli, Curr Pharm Des, vol. 16, no. 28 , p. $3185,2010$.

[3] U. Kazmaier, A. Bayer, and J. Deska, Synthesis, vol. 45, no. 11, p. 1462, 2013.

[4] U. Kazmaier, S. Maier, and F. L. Zumpe, Synlett, vol. 11, p. 1523, 2000 .

[5] A. Brik, Adv Synth Catal, vol. 350, no. 11-12, p. 1661, 2008.

[6] S. B. Höfling, C. Hultsch, H.-J. Wester, and M. R. Heinrich, Tetrahedron, vol. 64, no. 52, p. 11846, 2008.

[7] V. V. Rostovtsev, L. G. Green, V. V. Fokin, and K. B. Sharpless, Angew Chem Int Ed Engl., vol. 114, no. 14, p. 2708, 2002.

[8] Z. P. Demko and K. B. Sharpless, Angew Chem Int Ed Engl, vol. 41, no. 12 , p. $2113,2002$.

[9] J. M. Chalker, G. J. L. Bernardes, and B. G. Davis, Acc Chem Res, vol 44, no. 9 , p. 730,2011

[10] R. Kaul, S. Surprenant, and W. D. Lubell, J Org Chem, vol. 70, no. 10, p. 3838, 2005.

[11] C. E. Schafmeister, J. Po, and G. L. Verdine, J Am Chem Soc, vol. 122, no. 24 , p. 5891, 2000.

[12] C. Phillips, L. R. Roberts, M. Schade et al., J Am ChemSoc, vol. 133, no. 25 , p. $9696,2011$.

[13] D. J. Yeo, S. L. Warriner, and A. Wilson, J Chem Commun (Camb), vol. 49, no. 80, p. 9131, 2013.

[14] J. Kaiser, S. S. Kinderman, C. J. Bart van Esseveldt et al., Org. Biomol. Chem., vol. 3, pp. 3435 - 3467, 2005.

[15] J. P. Scannell, D. L. Pruess, T. C. Demny, F. Weiss, T. Williams, and A. Stempel, J. Antibiot., vol. 24, pp. 239-244, 1971.

[16] S.-I. Hatanaka, Y. Niimura, and K. Takishima, Trans. Mycol. Soc, Japan, vol. 26, pp. 61-68, 1985.

[17] E. S. Jounathan and E. Frieden, J. Biol. Chem., vol. 220, pp. 801-809, 1956.

[18] G. Burnett, P. Marcotte, and C. Walsh, J. Biol. Chem., vol. 255, pp. 3487-3491, 1980.

[19] G. A. Thompson, A. H. Datko, and S. H. Mudd, Plant Physiol., vol. 70, pp. 1347-1352, 1982

[20] M. Johnston, R. Raines, M. Chang, N. Esaki, K. Soda, and C. Walsh, J. Am. Chem. Soc.,vol. 20, pp. 4325-4333, 1981.

[21] M. Johnston, D. Jankowski, P. Marcotte, H. Tanaka, N. Esaki, K. Soda, and C. Walsh, Biochemistry, pp. 4690-4701, 1979.

[22] R. H. Abeles and C. T. Walsh, J. Am. Chem. Soc., vol. 95, pp. 6124-6125, 1973.

[23] M. Berkheij, Dissertation, Chapter 1, University of Amsterdam, Faculty of Science, p. 134, 2008

[24] Y. Niimura, F. Kinoshita, and S. I. Hatanaka, Trans. Mycol. Soc., Japan 1974,vol. 15, pp. 218.

[25] G. T. Crisp and T. A. Robinson, Tetrahedron, vol. 48, p. 3239, 1992.

[26] K. Lee, S. Y. Hwang, and C. H. Park, Bioorg. Med. Chem. Lett., vol. 9, p. 1013, 1999.

[27] P. D. Greenspan, K. L. Clark, R. A. Tommasi, S. D. Cowen et al., J. Med. Chem., vol. 44, p. 4524, 2001.

[28] A. S. Saghyan, S. G. Petrosyan, A. F. Mkrtchyan, G. M. Mkrtchyan, and P., Langer. Chem. Journ. of Armenia. vol. 66, no. 3, pp. 588-596, 2013.

[29] A. S. Saghyan and M. Nauka, Enantiomerically Pure Non Protein Amino Acids, p. 205, 2014.

[30] Y. N. Belokon, A. S. Saghyan, S. M. Djamgaryan, V. I. Bakhmutov, S. V. Vitt, A. S. Batsanov, Y. T. Struchkov, V. M. Belikov, J. Chem. Soc., issue 8, p. 2301, 1990

[31] Y N. Belokon', A. S. Saghiyan, S. M. Djamgaryan, B. I. Bakhmutov, and V. M. Belikov, Asymmetric Synthesis of $\beta$-Substituted $\alpha$-Amino Acids via a Chiral Ni(II) Complexes of Dehydroalanine, Tetrahedron, vol. 44 , no. 17 , pp. 5507-5514, 1988.

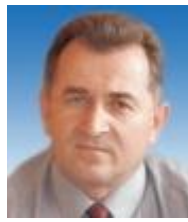

Ashot S. Saghyan is an Academician of NAS RA, and now is a Professor.

He was born in 1957 in Armenia. He got the chemistry $\mathrm{ScD}$ degree in 1997 , the $\mathrm{PhD}$ degree in chemistry in 1985. He is the director of the SPC "Armbiotechnology" SNPO NAS RA, the head of the Chair of Pharmchemistry and Pharmacognosy of Yerevan State

University. 


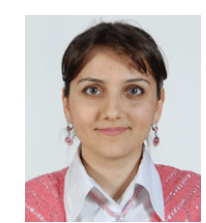

Anna F. Mkrtchyan is a $\mathrm{PhD}$ in chemistry. She was worn in 1986 in Armenia. She got the PhD degree in 2012. She is the head of laboratory of biomimetic catalysis of the SPC "Armbiotechnology" SNPO NAS RA, Assistant of the the Chair of Pharmchemistry and Pharmacognosy of Yerevan State University.

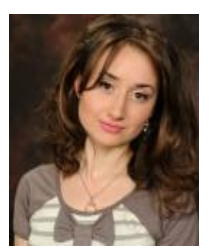

Ani J. Karapetyam was born in 1991 in Armenia. She got the MSc degree in 2014. She is with Junior Research of Laboratory of Biomimetic Catalysis of the SPC "Armbiotechnology" SNPO NAS RA, Laboratory Assistance of the Chair of Pharmchemistry and Pharmacognosy of Yerevan State University.

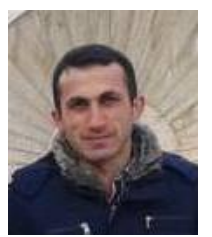

Zorayr Z. Mardiyan was born in 1989 in Armenia. He got the MSc degree in 2014. He is with Junior Research of Laboratory of Biomimetic Catalysis of the SPC “Armbiotechnology” SNPO NAS RA.

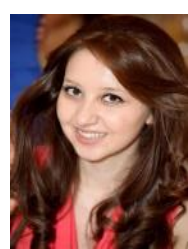

Liana A. Hayriyan was born in 1992 in Armenia. She got the MSc degree in 2015. She is an Laboratory Assistance of Laboratory of Biomimetic Catalysis of the SPC “Armbiotechnology” SNPO NAS RA.

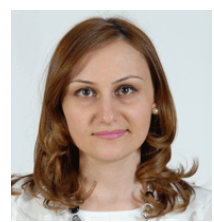

Hayarpi M. Simonyan is a $\mathrm{PhD}$ in Chemistry. She was worn in 1983in Armenia. She got the PhD degree in 2014. She is a researcher of Laboratory of Biomimetic catalysis of the SPC "Armbiotechnology" SNPO NAS RA, Assistant of the Chair of Pharmchemistry and Pharmacognosy of Yerevan State University. 